\title{
PENGARUH SENAM REMATIK TERHADAP PENURUNAN NYERI OSTEOARTRITIS PADA LANSIA DI PANTI SOSIAL TRESNA WERDHA NIRWANA PURI SAMARINDA
}

\author{
Amelia Dinartika'), Edi Purwanto2), Indah Nur Imamah' \\ ${ }^{1}$ Mahasiswa Prodi Sarjana Terapan Keperawatan, Poltekkes Kaltim \\ 2Jurusan Keperawatan, Poltekkes Kaltim \\ Email : Edipurwanto580@gmail.com
}

\begin{abstract}
Introduction: Pain is the most common complaints from seniors. Such care is required both pharmacologically and non-pharmacologically to lessen the seniors' pain. One of the non-pharmacological treatment to lessen the pain is rheumatic gymnast. The aim of this research is to determine the effect of rheumatic gymnast towards the decrease in Osteoarthritis pain on seniors.

Methods: This research uses quasi-experiment with pre and post-test control group design. Sampling method of probability sampling with simple random sampling. The number of sample for each group is 11 people. Interventions were done 7 times a week.

Results: From hypothesis test with Wilcoxon scores obtained that there is an effect of rheumatic gymnast towards the decrease in pain with $p$ value of 0,003 on intervention group, while on the control group there is no effect towards the decrease in pain with $p$ value of 0,157 .

Conclusions: There is significant effect towards the decrease in pain with $p$ value of $(0,003)$.

Suggestions: It is hoped for the next researchers to do the research with more respondents and longer time of research as well as considering more characteristics that could be the triggering factor which can make the result become bias.
\end{abstract}

Keywords: Rheumatic Gymnast, Osteoarthritis Pain.

\begin{abstract}
ABSTRAK
Pendahuluan: Nyeri merupakan keluhan yang paling sering dialami oleh lansia. Diperlukan penanganan baik secara farmakologi maupun nonfarmakologi untuk menurunkan nyeri pada lansia. Salah satu terapi non farmakologi untuk mengurangi nyeri yaitu dengan Senam Rematik. Tujuan penelitian ini adalah untuk mengetahui pengaruh Senam Rematik terhadap penurunan nyeri Osteoartritis pada lansia.

Metode: Penelitian ini menggunakan desain penelitian quasi experiment dengan pre and post test control group design. Metode sampling yaitu probability sampling dengan simple random sampling. Jumlah sampel pada masing-masing kelompok adalah 11 orang. Intervensi dilakukan sebanyak 7 kali seminggu.

Hasil: Dari uji hipotesis dengan Wilcoxon didapatkan hasil terdapat pengaruh Senam Rematik terhadap penurunan nyeri Osteoartritis dengan $p$ value 0,003 pada
\end{abstract}


kelompok intervensi, sedangkan pada kelompok kontrol tidak terdapat pengaruh terhadap penurunan nyeri dengan $\mathrm{p}$ value 0,157

Kesimpulan: Terdapat pengaruh yang bermakna terhadap penurunan nyeri dengan $p$ value $(0,003)$.

Saran: Diharapkan untuk peneliti selanjutnya agar dapat melakukan penelitian dengan jumlah responden yang lebih banyak dan kurun waktu yang lebih lama serta dapat mempertimbangkan lebih banyak karakteristik yang dapat menjadi faktor perancu yang dapat membuat hasil penelitian menjadi bias.

Kata Kunci: Senam Rematik, Nyeri Osteoartritis.

\section{PENDAHULUAN}

Setiap warga Negara Republik Indonesia memiliki hak memperoleh kesehatan sebagaimana yang dimaksud dalam pembukaan UndangUndang Dasar 1945. Dijelaskan lebih lanjut dalam UU No 36 tentang Kesehatan yang menyatakan bahwa setiap warga Negara Indonesia memiliki hak untuk mendapatkan pelayanan kesehatan yang bermutu, aman, terjangkau serta berhak untuk memilih pelayanan yang dikehendakinya. Sedangkan kewajiban Pemerintah yaitu menyediakan segala fasilitas kesehatan baik fisik maupun sosial untuk mencapai derajat kesehatan yang setinggi-tingginya (Kementerian Kesehatan RI, 2009).

Tercapainya derajat kesehatan masyarakat diiringi dengan bertambahnya populasi penduduk usia lanjut dan tingginya usia harapan hidup. Pada tahun 2015-2020 diperkirakan usia harapan hidup masyarakat Indonesia mencapai 70 tahun atau lebih (Maharani, 2007). Dengan terjadinya peningkatan angka harapan hidup mengakibatkan penyakit-penyakit yang berhubungan dengan lanjut usia yang seringkali disebut penyakit degeneratif meningkat, salah satunya ialah Osteoartritis.
Prevalensi penderita Osteoartritis menurut organisasi kesehatan dunia World Health Organization (WHO), pada tahun 2004 mencapai 151,4 juta jiwa dan 27,4 juta jiwa berada di Asia Tenggara. Prevalensi Osteoartritis di Indonesia berjumlah $5 \%$ pada usia $<40$ tahun, 30\% pada usia 40-60 tahun dan $65 \%$ pada usia $>61$ tahun (Bachtiar, 2010).

Berdasarkan data Dinkes Kota Samarinda (2017), jumlah kasus penyakit sendi seperti Osteoartritis dan gout pada tahun 2016 tercatat sebanyak 4.410 kasus dengan 2.239 kasus terjadi pada lansia. Sedangkan dari hasil studi pendahuluan yang dilakukan di Panti Sosial Tresna Werdha Nirwana Puri Samarinda pada tanggal 24 Oktober 2017, dari total 102 lansia diketahui sebanyak 36 lansia atau sekitar $36,72 \%$ mengalami Osteoartritis. Angka ini menempati urutan pertama diantara penyakit lainnya.

Osteoartritis merupakan penyakit persendian yang kasusnya paling umum dijumpai secara global, suatu penyakit kerusakan tulang rawan sendi yang berkembang lambat dan tidak diketahui penyebabnya, meskipun terdapat beberapa faktor resiko yang 
berperan. Keadaan ini berkaitan dengan usia lanjut (Sukanto, 2010).

Berdasarkan keberadaan nyeri akibat Osteoartritis ini, lansia yang menderita kemudian membatasi pergerakan pada bagian yang nyeri sehingga luas gerak sendi ke semua arah berkurang. Bila gerakan pasif lebih dominan dari pada gerakan aktif dapat menyebabkan kekakuan dan gangguan pada otot sendi (Isbagio, 2005).

Nyeri yang bertahan lama dapat menghentikan secara permanen fungsional sendi. Penghentian fungsional sendi ini dapat membatasi aktivitas fisik lansia, selanjutnya lansia mengalami penurunan dari quality of life (Hopman-Rock et al.,2007). Sehingga adanya latihan fisik merupakan tindakan promotif sebagai upaya untuk mencegah dan meringankan nyeri serta berfungsi sebagai terapi tambahan, salah satu latihan fisik yaitu Senam Rematik.

Senam Rematik merupakan salah satu metode yang praktis dan efektif memelihara kesehatan tubuh. Gerakan yang terkandung dalam Senam Rematik adalah gerakan yang sangat efektif, efisien, dan logis karena rangkaian gerakannya dilakukan secara teratur dan terorganisasi bagi penderita Osteoartritis (Nugroho, $\mathrm{H}$. Wahyudi, B.SC., 2008). Hal ini dibuktikan dengan beberapa peneliti yang melakukan penelitian tentang pemberian latihan Senam Rematik pada lansia.

Penelitian yang dilakukan tahun 2007 tentang tindakan Non Farmakologis berupa latihan fisik yang diberikan pada penderita Osteoartritis terbukti berpengaruh dalam penurunan nyeri sendi dan memberikan efek positif dalam meningkatkan kekuatan sendi. Salah satu dari latihan fisik yang sederhana dan mudah dilakukan adalah Senam Rematik (Nurhidayah, 2012).

Penelitian yang dilakukan oleh Suhendriyo (2014), tentang pengaruh Senam Rematik terhadap pengurangan rasa nyeri pada penderita Osteoartritis lutut di Karangasem Surakarta. Hasil penelitian ini menggambarkan bahwa terdapat pengaruh yang signifikan dalam pemberian Senam Rematik terhadap pengurangan rasa nyeri pada penderita Osteoartritis lutut di Karangasem Surakarta dilihat dari nilai $\mathrm{p}=0,005$ pada kelompok kontrol maupun pada kelompok perlakuan (Suhendriyo, 2014).

Berdasarkan latar belakang tersebut, maka peneliti tertarik melakukan penelitian "Pengaruh Senam Rematik terhadap Penurunan Nyeri Osteoartritis pada Lansia di Panti Sosial Tresna Werdha Nirwana Puri Samarinda".

\section{BAHAN DAN METODE PENELITIAN Lokasi Penelitian}

Penelitian ini dilakukan di Panti Sosial Tresna Werdha Nirwana Puri Samarinda di wisma responden secara door to door. Waktu pelaksanaan penelitian mulai April hingga Mei 2018.

\section{Rancangan Penelitian}

Penelitian ini menggunakan desain quasi experiment pre test and post test control group dengan 2 kelompok randomisasi.

\section{Populasi dan Sampel}

Populasi dalam penelitian ini adalah seluruh lansia di Panti Sosial 
Tresna Werdha Nirwana Puri Samarinda. Sampel dalam penelitian ini berjumlah 22 orang dan ditetapkan berdasarkan kriteria inklusi.

\section{Metode Pengumpulan Data}

Data awal dikumpulkan melalui observasi dan wawancara, sedangkan data pre dan post dikumpulkan melalui lembar penilaian nyeri NRS pada lansia yang mengalami nyeri Osteoartritis.

\section{Analisis Data}

Data yang telah dikumpulkan diuji terlebih dahulu menggunakan uji normalitas dan homogenitas kemudian dianalisis menggunakan uji wilcoxon untuk mengetahui pengaruh Senam Rematik terhadap penurunan nyeri Osteoartritis.

\section{HASIL PENELITIAN}

Karakteristik

responden

berdasarkan usia sebagian responden berusia antara 60-74 tahun dengan persentase $50 \%$, usia $75-90$ tahun sebesar $40,9 \%$, dan $9,1 \%$ yakni berusia $>90$ tahun. Karakteristik responden berdasarkan jenis kelamin menunjukkan bahwa presentase terbesar pada lansia perempuan sebanyak $63,6 \%$ dari 22 responden.

Analisis pengaruh sebelum dan setelah diberikan intervensi pada kelompok intervensi dan kontrol untuk skala nyeri menggunakan Wilcoxon.

Berdasarkan uji beda rerata didapatkan hasil bahwa pada kelompok intervensi nilai mean dan standar deviasi skala nyeri sebelum dilakukan intervensi adalah

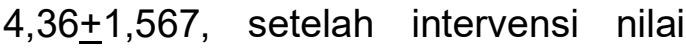
mean dan standar deviasinya adalah $1,36 \pm 1,36$, nilai $p$ yang didapat yaitu $0,003<0,05$, sehingga dapat disimpulkan bahwa ada pengaruh Senam Rematik terhadap penurunan nyeri Osteoartritis pada kelompok intervensi. Sedangkan pada kelompok kontrol mean dan standar deviasi skala nyeri sebelum diberikan intervensi adalah $3,27 \pm 1,954$, setelah intervensi $3,09 \pm 3,09$. Berdasarkan hal tersebut didapatkan $p$ value 0,157>0,05, sehingga dapat disimpulkan bahwa tidak ada pengaruh Senam Rematik terhadap penurunan nyeri Osteoartritis pada kelompok kontrol.

\section{PEMBAHASAN}

\section{Karakteristik Responden}

Hasil penelitian yang dilakukan pada 22 orang responden penderita nyeri Osteoartritis di Panti Sosial Tresna Werdha Nirwana Puri Samarinda terbagi menjadi 2 kelompok, yakni kelompok intervensi dan kelompok kontrol. Hasil penelitian ini menunjukkan rata-rata usia responden 60-74 tahun sebesar $50 \%$. Hal ini sesuai dengan Departemen Kesehatan RI (2009) yang mengatakan bahwa usia lebih dari 60 tahun merupakan kelompok usia risiko tinggi mengalami penurunan fungsi sistem tubuh dibanding lansia yang berusia kurang dari 60 tahun. Hal tersebut juga didukung oleh penelitian Stanley \& Beare (2007), yang mengatakan kemunduran sistem muskular dipercepat setelah umur 60 tahun dan sendi juga mengalami kemunduran kartilago yang memungkinkan terjadinya nyeri sendi.

Sedangkan distribusi frekuensi responden berdasarkan jenis kelamin diperoleh data terbesar adalah lansia perempuan, yakni $63,6 \%$ dari 22 responden. Hal tersebut didukung oleh 
penelitian (Nursarifah, 2011) yang menyebutkan bahwa Osteoartritis lutut umumnya terjadi dua kali lipat pada lansia perempuan dibanding lansia laki-laki. Lansia perempuan mengalami perubahan hormonal yaitu penurunan hormon estrogen sehingga berisiko menyebabkan tulang keropos.

Distribusi frekuensi responden berdasarkan aktivitas fisik yang sering dilakukan sebanyak masing-masing 9 responden atau sekitar 40,9\% melakukan aktivitas dengan berolahraga dan jalan-jalan, sedangkan 4 responden atau sekitar $18,2 \%$ melakukan aktivitas sehari-hari dengan bersih-bersih.

Distribusi frekuensi responden berdasarkan riwayat trauma, dapat disimpulkan bahwa sebagian besar responden pernah mengalami trauma sebesar $54,5 \%$ atau sebanyak 12 lansia dari 22 responden.

Distribusi frekuensi responden berdasarkan lama menderita diperoleh data sebesar $36,4 \%$ atau 8 lansia mengalami nyeri $>3$ bulan, sedangkan presentase terkecil yaitu 1 lansia mengalami nyeri sekitar 3 bulan terakhir sebesar 4,5\%.

Nyeri pre test dan post test kelompok intervensi

Hasil uji Wilcoxon didapatkan nilai $p$ value $(0,003)$ yang berarti ada pengaruh Senam Rematik terhadap nyeri Osteoartritis. Hal ini didukung penelitian yang dilakukan oleh Suhendriyo (2014), tentang pengaruh Senam Rematik terhadap pengurangan rasa nyeri pada penderita Osteoartritis lutut di Karangasem Surakarta.

Nyeri pre test dan post test kelompok kontrol
Hasil uji Wilcoxon didapatkan nilai $p$ value $(0,157)$ yang berarti tidak ada pengaruh penurunan nyeri pada kelompok kontrol.

Perbedaan penurunan nyeri kelompok intervensi dan kelompok kontrol

Setelah dilakukan pengolahan data dan menguji hasil penelitian dengan mengunakan uji Mann-Whitney Test dapat diketahui bahwa ada pengaruh pemberian Senam Rematik terhadap penurunan nyeri Osteoatritis pada lansia dimana hasil yang diperoleh $p$ value (0.012) yang artinya ada pengaruh yang signifikan. Hal ini didukung dengan hasil penelitian dari Suhendriyo (2014) yang menggambarkan bahwa terdapat pengaruh yang signifikan dalam pemberian Senam Rematik terhadap pengurangan rasa nyeri pada penderita Osteoartritis lutut di Karangasem Surakarta dilihat dari nilai $\mathrm{p}=0,005$ pada kelompok kontrol maupun pada kelompok perlakuan (Suhendriyo, 2014).

Senam Rematik adalah salah satu metode yang praktis dan efektif memelihara kesehatan tubuh. Gerakan yang terkandung dalam Senam Rematik adalah gerakan yang sangat efektif, efisien, dan logis karena rangkaian gerakannya dilakukan secara teratur dan terorganisasi bagi penderita Osteoartritis (Nugroho, $\mathrm{H}$. Wahyudi, B.SC., 2008).

Tindakan Senam Rematik dalam upaya menurunkan nyeri bekerja dengan mengurangi rangsang pada ujung saraf atau memblokir arah berjalannya impuls nyeri yang menuju ke otak. Pada daerah nyeri akan memberikan sinyal ke hipotalamus 
melalui sumsum tulang belakang. Ketika reseptor panas di hipotalamus diberi rangsangan, sistem efektor mengeluarkan sinyal dan menyebabkan terjadinya vasodilatasi perifer. Vasodilatasi ini menyebabkan aliran darah meningkat sehingga suplai oksigen ke jaringan lancar dan metabolisme jaringan ikut meningkat (Tamsuri, 2012).

Pada penelitian ini peneliti mengambil responden yang mengalami nyeri Osteoartritis tanpa mempertimbangkan lokasi sendi yang mengalami nyeri. Pada penelitian sebelumnya tidak dijelaskan apakah letak sendi tertentu rentan terhadap terjadinya nyeri serta apakah lokasi nyeri tersebut mempengaruhi perubahan skala nyeri setelah diberi Senam Rematik. Menurut peneliti, lokasi nyeri juga dapat dipertimbangkan karena letak sendi yang berbeda dapat mempengaruhi perubahan nilai nyeri setelah diberi Senam Rematik. Dalam penelitian ini, sebagian besar responden mengalami nyeri di bagian lutut dan jari-jari. Hal ini dikarenakan lutut merupakan anggota gerak ekstremitas bawah yang fungsinya menyokong tubuh saat berdiri maupun berjalan, sehingga sendi lutut menjadi sendi utama yang sering mengalami nyeri pada lansia dibandingkan sendi-sendi lainnya jarijari. Selain itu nyeri sendi pada ekstremitas atas lebih cepat mengalami penurunan nyeri dibandingkan nyeri sendi pada ekstremitas bawah dikarenakan letaknya yang dekat dengan sumsum tulang belakang dan hipotalamus, bagian dari otak tempat dimana impuls nyeri dihantarkan.

\section{KESIMPULAN DAN SARAN}

Berdasarkan pembahasan di atas dapat disimpulkan bahwa karakteristik usia responden sebagian besar adalah berusia 60-74 tahun atau sebesar $54,5 \%$, karakteristik berdasarkan jenis kelamin sebagian besar responden adalah perempuan sebesar $63,6 \%$ atau sebanyak 14 lansia, karakteristik berdasarkan aktivitas fisik yang sering dilakukan 40,9\% melakukan olahraga dan jalan-jalan, karakteristik berdasarkan riwayat trauma dapat disimpulkan responden pernah mengalami trauma sebesar 54,5\% atau 12 responden, sedangkan karakteristik berdasarkan lama menderita presentase terbesar yaitu lansia dengan nyeri $>3$ bulan.

Tingkat nyeri sebelum perlakuan didapatkan hasil $59,2 \%$ atau 13 lansia mengalami nyeri ringan, nyeri sedang sebasar $31,8 \%$, dan nyeri berat $9 \%$.

Setelah diberi perlakuan didapatkan hasil uji Wilcoxon $p$ value $(0,003)$ yang berarti ada pengaruh Senam Rematik terhadap nyeri Osteoartritis. sedangkan pada kelompok kontrol didapatkan hasil uji Wilcoxon $p$ value $(0,157)$ yang berarti tidak ada pengaruh.

Pada penelitian ini dilakukan uji mann-withney dan didapatkan nilai $p$ value $(0,003)$ sehingga dapat disimpulkan bahwa ada pengaruh Senam Rematik terhadap penurunan nyeri Osteoartritis pada lansia.

Bagi peneliti selanjutnya diharapkan agar dapat melakukan penelitian dengan jumlah responden yang lebih banyak dan kurun waktu yang lebih lama serta dapat mempertimbangkan lebih banyak karakteristik yang dapat menjadi faktor 
perancu yang dapat membuat hasil penelitian menjadi bias.

\section{DAFTAR PUSTAKA}

Andarmoyo, S. (2013) Konsep \& Proses Keperawatan Nyeri. Yogyakarta

Arikunto, S. (2006) Prosedur Penelitian: Suatu Pendekatan Praktik. Jakarta: Rineka Cipta.

Bachtiar, A. (2010) 'Pengaruh ekstrak jahe (ZINGIBER OFFICINALE) terhadap Tanda dan Gejala Osteoartritis pada Pasien Rawat Jalan di Puskesmas Pandan Wangi Kota Malang'.

Black and Hawks (2009) Medical Surgical Nursing Clinical Management for Positive Outcomes. St. Louis: Missouri Elsevier Saunders.

Brunelli, C. et al. (2010) 'Earch Comparison of Numerical and Verbal Rating Scales to Measure Pain Exacerbations in Patients with Chronic Cancer Pain', Health and Quality of Life Outcomes, 8.

Dharma, K. K. (2011) Metodologi Penelitian Keperawatan. Jakarta Timur: Trans Info Media (TIM).

Felson (2008) 'Universitas Sumatera Utara', pp. 5-23.

Heri, K. (2014) 'Pengaruh senam rematik terhadap nyeri sendi pada lansia di Panti Sosial Tresna Werdha Budimulia 04 Margaguna Jakarta Selatan. Jurnal Mahasiswa Program Keperawatan Universitas Esa Unggul, 1(1), h.1-10.'

Hidayat, A. A. A. (2008) Pengantar Konsep Dasar Keperawatan. Jakarta: Salemba Medika.
Hopman-Rock, Kraaimaat, M.F.W., \& Bijlsma, J.W.J. (2003). Quality of life in elderly subjects with pain in the hip or knee. Quality of Life Research, 6(1), p.67-68.

Isbagio, H. (2005). Pendekatan diagnostik penyakit rematik. Sybbagian Reumatologi. Bagian IImu Penyakit Dalam Fakultas Kedokteran Universitas Indonesia/ Rumah Sakit Dr. Cipto Mangunkusumo. Jakarta: Cermin Dunia Kedokteran, h.12.26.

Judha (2012) Teori Pengukuran Nyeri dan Nyeri Persalinan. Yogyakarta: Nuha Medika.

Kambayana, G. (2011) 'Korelasi Kadar Matrix Metalloproteinases 3 (Mmp3) Dengan Derajat Beratnya Osteoartritis Lutut.'

Kementerian Kesehatan RI (2009) 'Undang-Undang Republik Indonesia No. 36 Tahun 2009 Tentang Kesehatan', p. 111.

L, H. (2007) Pengapuran sendi atau osteoartritis. Edited by Perhimpunan and R. Indonesia.

Maharani, E. P. (2007) Tesis FaktorFaktor Risiko Osteoartritis Lutut (Studi Kasus di Rumah Sakit Dokter Kariadi Semarang).

Muhlisin, dr. A. (2018) Menilai Skala Nyeri, Mediskus.

Nugroho, H. Wahyudi, B.SC., S. (2008) Keperawatan Gerontik \& Geriatrik. Edisi 3. Edited by penerbit buku kedoteran EGC. Jakarta.

Nurhidayah, K. (2012) 'Pengaruh senam rematik terhadap aktifitas fungsional lansia di komunitas senam lansia Wilayah Kelurahan Nusukan Banjarsari Surakarta, Muhammadiyah Surakarta, Solo'. 
Nursalam (2008) Konsep dan penerapan metodologi penelitian keperawatan. Jakarta.

Nursarifah, R. (2011) 'Hubungan Antara Obesitas Dengan Kejadian Osteoartritis Lutut Di RSUP dr. Kariadi Semarang. (Skripsi). Semarang. FK UNIMUS.'

Pfizer (2008) 'Khikmah Nurhidayah Diploma Iv Fisioterapi'.

Potter, P. A. dan A. G. P. (2009) Fundamental Keperawatan Buku 1 Ed. 7. Edited by Salemba Medika. Jakarta.

Potter, P. A. and Perry, A. G. (2010) 'Foundamental Of Nursing', in. Jakarta: Salemba Medika.

Prasetyo, S. N. (2010) Konsep dan Proses Keperawatan Nyeri. Yogyakarta: Graha IImu.

Sitinjak, V. M. (2016) 'Pengaruh Senam Rematik terhadap Perubahan Skala Nyeri pada Lanjut Usia dengan Osteoartritis
Lutut.'

Soeroso, J. (2008) 'Pedoman Penggunaan Obat Anti Inflamasi Non Steroid'.

Suhendriyo (2014) 'Pengaruh Senam Ramathik Terhadap Pengurangan Rasa Nyeri Pada Penderita Osteoarhritis Lutut Di karangasem Surakarta. Jurnal Terpadu IImiah Kesehatan.'

Sukanto, E. \& H. (2010a) Konsep Dan Penerapan Metodologi Penenlitian IImu Keperawatan. Edited by Medika Salemba. Jakarta.

Sukanto, E. \& H. (2010b) Konsep Dan Penerapan Metodologi Penenlitian IImu Keperawatan. Jakarta: Medika Salemba.

Tamsuri, A. (2012) Konsep \& Penatalaksanaan Nyeri. Jakarta: EGC. 
Lampiran

1. Tabel 1 (Distribusi Karakteristik Responden)

Tabel 1

Distribusi Frekuensi Berdasarkan Karakteristik Responden

Senam Rematik di Panti Sosial Tresna Werdha Nirwana Puri

Samarinda

\begin{tabular}{lrr}
\hline \multicolumn{1}{c}{ Karakteristik } & N & \% \\
\cline { 2 - 3 } Usia (Tahun) & & \\
$60-74$ & 11 & $50 \%$ \\
$75-90$ & 9 & $40,9 \%$ \\
$>90$ & 2 & $9,1 \%$ \\
Jenis Kelamin & & \\
Laki-laki & 8 & $36,4 \%$ \\
Perempuan & 14 & $63,6 \%$ \\
Total & $\mathbf{2 2}$ & $\mathbf{1 0 0 \%}$ \\
Sumber: Analisis data primer, 2018 &
\end{tabular}

2. Tabel 2 (Uji Mann Withney)

Tabel 2

Perbedaan Nyeri Pre test dan Post test Kelompok Intervensi dan Kelompok Kontrol

\begin{tabular}{ccccc}
\hline Kelompok & $\mathbf{N}$ & Mean & SD & P value \\
\hline Intervensi & & & & \\
Pre test & 11 & 4,36 & 1,567 & 0,003 \\
Post test & & 1,36 & 1,36 & \\
Kontrol & & & & \\
Pre test & 11 & 3,27 & 1,954 & 0,157 \\
Post test & & 3,09 & 3,09 & \\
\hline
\end{tabular}

Sumber: Analisis data primer, 2018 